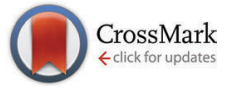

Cite this: Phys. Chem. Chem. Phys., 2015, 17, 24476

DOI: $10.1039 / c 5 c p 90157 j$

www.rsc.org/pccp

\section{Correction: The transformation from amorphous iron phosphate to sodium iron phosphate in sodium-ion batteries}

\author{
Yao Liu, ${ }^{a}$ Yirong Zhou, ${ }^{a}$ Junxi Zhang, ${ }^{* a}$ Shiming Zhang ${ }^{\text {ab }}$ and Shuojiong $\mathrm{Xu}^{\mathrm{a}}$ \\ Correction for 'The transformation from amorphous iron phosphate to sodium iron phosphate in \\ sodium-ion batteries' by Yao Liu et al., Phys. Chem. Chem. Phys., 2015, 17, 22144-22151.
}

The authors would also like to acknowledge the financial support of the Shanghai Science \& Technology Commission Project 13NM1401400. The amended Acknowledgements are as shown below:

This study was carried out with the financial support of the Shanghai Science \& Technology Commission Project 13NM1401400, the Shanghai Science \& Technology Commission Project 14DZ2261000, the Ability Development of Shanghai Science \& Technology Commission Project 09230501400, and the Research Foundation of the Ministry of Education (No. 20502). We thank ProofReading-Service.com (http://www.proof-reading-service.com/) for its linguistic assistance during the preparation of this manuscript.

The Royal Society of Chemistry apologises for these errors and any consequent inconvenience to authors and readers.

\footnotetext{
${ }^{a}$ Shanghai Key Laboratory of Materials Protection and Advanced Materials in Electric Power, Shanghai University of Electric Power, Shanghai, 200090,

People's Republic of China. E-mail: zhangjunxi@shiep.edu.cn; Fax: +86-21-35303677; Tel: +86-21-35303677

${ }^{b}$ State Key Laboratory of Silicon Materials, Key Laboratory of Advanced Materials and Applications for Batteries of Zhejiang Province \& Department of Materials Science and Engineering, Zhejiang University, Hangzhou 310027, People's Republic of China
} 